\title{
Competition in Healthcare: Good, Bad or Ugly?
}

\author{
Maria Goddard*
}

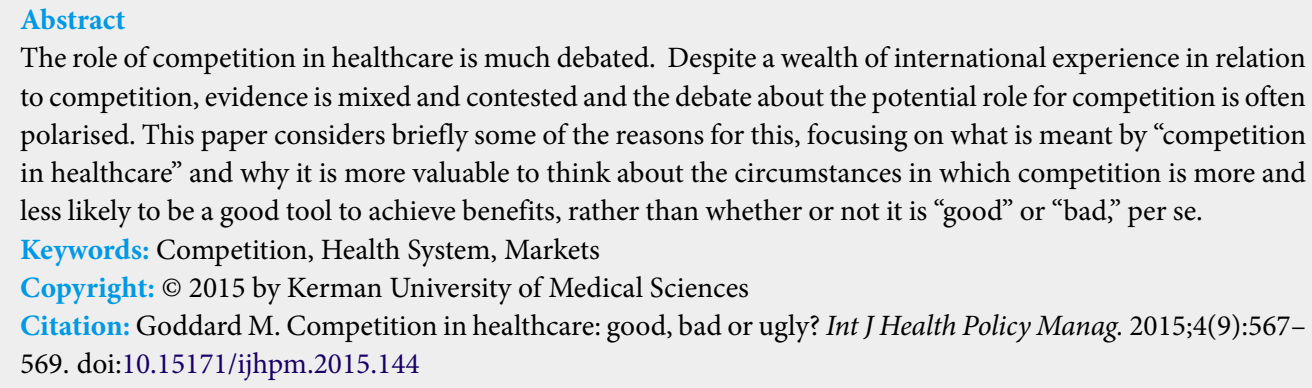

The role of competition in healthcare is much debated. Despite a wealth of international experience in relation to competition, evidence is mixed and contested and the debate about the potential role for competition is often polarised. This paper considers briefly some of the reasons for this, focusing on what is meant by "competition in healthcare" and why it is more valuable to think about the circumstances in which competition is more and less likely to be a good tool to achieve benefits, rather than whether or not it is "good" or "bad," per se.

Keywords: Competition, Health System, Markets

Copyright: @ 2015 by Kerman University of Medical Sciences

Citation: Goddard M. Competition in healthcare: good, bad or ugly? Int J Health Policy Manag. 2015;4(9):567569. doi:10.15171/ijhpm.2015.144

Article History:

Received: 17 July 2015

Accepted: 30 July 2015

ePublished: 1 August 2015
$\mathrm{T}$ The organisation of healthcare has been a subject of debate for a very long time. There are many facets to the debate but one of the most intensely argued is the appropriate role of competition in healthcare markets. Claims are made at each end of the spectrum: some see competition as having no place in services aimed at protecting the sick ${ }^{1}$; and others that competition is the antidote for bloated, inefficient services and even "saves lives.",3 Given both the variety of models operating between countries and also the regular changes that occur within countries where competitive forces are at times in favour and other times not, it is perhaps surprising that we do not appear to have sufficient evidence from comparison of different practices, to settle this debate. There are at least 2 reasons for this: first, "competition in healthcare" is a broad term that does not capture adequately the many variations and meanings of the term; second, even when defined carefully, evaluation of the impact of competition is far from straightforward. I consider these points further below.

From a simple economics perspective, a competitive market is one in which buyers and sellers come together in an exchange relationship and if this were a "perfect" market, exhibiting certain characteristics, theory would predict that this would deliver the best possible outcomes for both buyers and sellers. In reality, even the keenest proponents of competition are unlikely to argue that the restrictive conditions under which such outcomes are achieved, will exist in healthcare markets which are characterised by serious imperfections or "failures" (such as buyers inability to determine quality), and thus it has long been held ${ }^{4}$ that healthcare almost everywhere, is provided in the context of regulated markets, sometimes called "quasi-markets." Therefore, the debate is about the degree of competition, as well as the degree of regulation (from central, federal, regional, or local governments), that will produce the best outcomes, rather than between competition versus no competition.

All too often, arguments are blurred by the tendency to equate competition with the private sector/privatisation and lack of competition with the public sector. Things become even more muddled when the financing and delivery of healthcare are not considered separately. There are many ways of analysing the role of competition but starting with financing, whilst many systems have insurance coverage provided by a national, local or common insurer (singlepayer system), some healthcare systems operate with multiple and competing insurers, even where such insurance is compulsory. In some cases, for instance The Netherlands and Switzerland, the degree of actual competition is tempered by government regulation; and in others, although there are multiple insurers in operation, affiliation to one of these is not a matter of individual choice, but is determined by other factors such as professional status. The United States is notable in terms of operating a competitive insurance market (outside of Medicare and Medicaid), but there is also a small number of other countries which allow insurers to compete for the business of citizens, with some countries having more than 5 options from which citizens can choose. Some countries (eg, Ireland) may be moving towards multiple payer systems. ${ }^{5}$ In low- and middle-income countries (LMIC), the debate on the financing side is centred more around financial protection and in the quest for universal coverage there are many possible configurations that involve competition to one degree or other. ${ }^{6}$

The potential benefits of having competing insurers depend on key features of the healthcare market, including the degree to which insurers compete for customers - which in principle may drive down premiums; and also the degree to which they can influence the supply-side of the market which may reduce prices and improve quality if the structure of the market incentivises purchaser pressure on providers. However, even amongst the less regulated markets, there is generally a degree of control and regulation exercised over (a) the level of premium that can be charged (or the factors governing differential charges made to specific groups); and 
(b) the content of the benefits package (usually in terms of a minimum set of benefits). ${ }^{7}$ Regulation is aimed at guarding against market failure and, in the insurer market, factors related to imperfect information, moral hazard and adverse selection are particularly pertinent issues.

Competition in the delivery of healthcare services is relevant to a much broader range of healthcare systems across the world, but what it means is also not always clear. First, it is not synonymous with private sector provision as it possible to create competitive conditions amongst public sector providers, hence the "internal market" created in the English National Health Service (NHS). ${ }^{8}$ In such systems, some of the potential benefits of competition (eg, sharper focus on costs and quality) were intended to flow from the fact that providers were competing for contracts from purchasers/ commissioners. Second, privately owned providers may be publically funded and may operate in competition with publically owned providers. Third, competition is not always purely price-based; for example, the introduction of fixed tariffs/prices in the NHS still allowed for competition on non-price aspects of care, as well as giving a greater role to consumers in stimulating competition via exercising choice over which provider they go to for some types of care. Fourth, the characteristics of many healthcare systems often inhibits the degree to which there can be competition in the market ie, with providers competing for patients; and instead it is often more about providers competing for the market (or making markets contestable) ie, trying to win the business of a commissioner where it is feasible to only have one or very few providers of a service, operating. In all such markets, regulation of providers will exist in some form or other and in the provider market issues related to the protection of citizens (eg, against price increases or quality skimping) as well as guarding against costly excess capacity or duplication in provision, are particularly pertinent.

A simple dichotomy between competitive and noncompetitive markets gets in the way of understanding the nuances of the reality of most healthcare systems which tend not to be at either end of these extremes. The complexity and diversity of competitive markets may be one reason why evidence on their impact, although plentiful, is often conflicting and non-generalisable beyond the specific context in which the evaluation has taken place, explaining perhaps why there are such diverse views on the role of competition. In addition, gathering reliable evidence on the impact of competition is hindered by the lack of robust evaluation frameworks when policies are implemented. Thus, the evidence relating to the English NHS which has, at various times seen elements mainly of supply-side competition introduced, is mixed, contested and likely applicable only in those countries with similar healthcare systems. For instance, the evidence relating to the later stages of the reforms (post 2000) is relevant to markets where prices are fixed by the regulator, and the main focus has been on whether competition in these circumstances has driven up quality. Studies that have strong methodological designs show that areas with greater competition had fewer deaths from myocardial infarction and hence are interpreted as a signal of improved quality. ${ }^{9,10}$ Reviews of the evidence from the period where there was both price and quality competition in the NHS, have suggested there is substantial evidence that there was either little effect on quality, or even that although observable quality measured by indicators such as waiting times, improved, non-observable measures such as hospital mortality rates, were adversely affected. ${ }^{11}$ Much of the evidence relating to price competition comes from the United States and whilst there is evidence to suggest that quality may indeed suffer under such a regime, hence the often held view that competition is "bad," detailed reviews of the literature again reveal quite a mixed picture. ${ }^{12,13}$ It is particularly difficult to generalise to LMIC from the experience of competitive healthcare markets in Europe and the United States, for the very reason that the implementation is so specific to the healthcare systems. In LMIC, the debate has anyway often centred around the role of private ownership of providers, rather than competition per se, as private provision is very common in many parts of Africa and Asia. ${ }^{14}$ Again, the evidence on the benefits - in terms of a range of factors reflecting performance - of private versus public providers is rather mixed, with no firm conclusions drawn ${ }^{15,16}$; and with evidence suggesting that there are pros and cons of systems with predominantly public versus private systems, in LMICs. ${ }^{17}$ However, although private ownership often goes hand in hand with a more market-based, competitive environment, it is not synonymous with competition as such markets can be highly regulated. In many LMICs in particular, regulation is often patchy in practice and has led some commentators to conclude that many of the market failures that may limit the role of competition in healthcare-most specifically, the lack of availability of information on quality and lack of managerial skills required-are often particularly apparent in LMIC. ${ }^{18}$ Others are more optimistic and see a greater potential role for market mechanisms in improving efficiency in developed and emerging economies, including competition between insurers and between providers. ${ }^{19}$

This raises another important issue in the debate which is the mechanism by which competition may produce benefits in the context of healthcare. Much of the focus has been on the role of patients exercising choice about where they receive care, hence the argument is that, where they are not paying a direct price, they are responding to signals about non-price aspects of the services on offer, and hence their behaviour can drive up overall quality. ${ }^{20}$ This can only apply where patients have a direct choice of provider and where there is competition in the market-for example, elective care in the NHS system. Although some have argued that driving up the quality of one aspect of care offered by a provider, may also have a positive impact on the quality of the provider across the board, ${ }^{21}$ and indeed others have investigated improvements in "management quality" that arise due to competitive pressures, which potentially impact on all hospital activity. ${ }^{22}$ Otherwise, the mechanism works through the agents of patients (commissioners, insurers) exercising choice on their behalf and directing business (in the market or for the market) only to those who offer a service that is value for money in terms of price (where prices are not fixed) and/or quality.

It is noticeable that the majority of the discussion and evidence about supply-side healthcare competition revolves around the hospital sector. ${ }^{13}$ Whilst such care is obviously a major element of healthcare provision, it may well be the case 
that the conditions most amenable to competitive markets exist more often in other sectors such as community care, where there are potentially fewer concerns about issues such as economies of scale and high entry costs. Indeed, this highlights the key issue in considering the role of competition - the debate should be less about endlessly discussing whether it is "good" or "bad" and more about defining the circumstances under which it may work well and the nature of the barriers that arise in other contexts. The influencing factors are complex and varied, including issues related to the demand side, such as whether patients are willing to travel in order to receive a service; technical issues related to the costs of providing services, such as the existence of economies of scale and scope and the degree of spare capacity that can be tolerated; and the ease by which information about services and quality may be accessed and interpreted (by patients or by their agent). Some research has focused on defining a "competition feasibility framework" against which the potential for competition for a specific service may be tested. ${ }^{23}$ Hence, a service such as community-based mental healthcare may exhibit characteristics that make it far more amenable to deriving benefits within a competitive environment, than provision of major trauma services, for instance.

The position taken on the appropriateness of competition in healthcare is also a political and cultural matter which is linked to the values inherent in the healthcare systems of different countries. In some contexts, any amount of competition may be seen as "too much" and as a signal of creeping "privatisation" and of the dismantling of dearly loved public systems. In others, the introduction of competition is welcomed as a potential mechanism for improving efficiency and productivity and improving population health. The fact that competition can be viewed both as the "problem" and the "solution" is an indication of the crucial role of context in understanding the potential for market forces to improve the healthcare system.

\section{Ethical issues}

Not applicable.

\section{Competing interests}

Author declares that she has no competing interests.

Author's contribution

MG is the single author of the manuscript.

\section{References}

1. Pollock A, Macfarlane A, Kirkwood G, et al. No evidence that patient choice in the NHS saves lives. Lancet. 2011;378(9809):2057-2060. doi:10.1016/S01406736(11)61553-5

2. Gaynor M, Moreno-Serra R, Propper C. Death by market power: reform, competition, and patient outcomes in the National Health Service. Am Econ J Econ Policy. 2013;5(4):134-166. doi:10.1257/pol.5.4.134

3. Kessler DP, McClellan MB. Is hospital competition socially wasteful? Q J Econ. 2000;115(2):577-615. doi:10.1162/003355300554863

4. Arrow KJ. Uncertainty and the welfare economics of medical care. Am Econ Rev. 1963;53(5):941-973.
5. Mikkers M, Padhraig R. "Managed competition" for Ireland? The single versus multiple payer debate. BMC Health Serv Res. 2014;14:442. doi:10.1186/1472-6963-14-442

6. Mills A. Health care systems in low- and middle-income countries. NEngl J Med. 2014;370:552-557. doi:10.1056/NEJMra1110897

7. Paris V, Devaux M, Wei L. Health Systems Institutional Characteristics: A Survey Of 29 OECD Countries. OECD Health Working Paper No. 50. Paris: OECD Publishing; 2010. doi:10.1787/5kmfxfq9qbnr-en

8. Baggott R. Evaluating health care reform: the case of the NHS internal market. Public Adm. 1997;75(2):283-306. doi:10.1111/1467-9299.00061

9. Cooper Z, Gibbons S, Jones S, McGuire A. Does hospital competition save lives? Evidence from the English NHS patient choice reforms. Econ J. 2011;121:F228-F260. doi:10.1111/ j.1468-0297.2011.02449.x

10. Gaynor M, Moreno-Serra R, Propper C. Death by Market Power: Reform, Competition and Patient Outcomes in the National Health Service. NBER Working Paper No. 16164. Cambridge, MA: National Bureau of Economic Research; 2010.

11. Bevan G, Skellern M. Does competition between hospitals improve clinical quality? A review of evidence from two eras of competition in the English NHS. BMJ. 2011;343:d6470. doi:10.1136/bmj.d6470

12. Gaynor M, Town RJ. Competition in Health Care Markets. In: Pauly MV, Mcguire TG, Barro PP, eds. Handbook of Health Economics. Vol 2. Elsevier; 2011:499-637. doi:10.1016/B978-0444-53592-4.00009-8

13. OECD Report. Competition in Hospital Services. http://www. oecd.org/daf/competition/50527122.pdf. Published 2012.

14. Forsberg BC, Montagu D, Sundewall J. Moving towards indepth knowledge on the private health sector in low- and middle-income countries. Health Policy Plan. 2011;26(1):i1-i3. doi:10.1093/heapol/czr050

15. Hollingsworth $B$. The measurement of efficiency and productivity of health care delivery. Health Econ. 2008;17(10):1107-1128. doi:10.1002/hec.1391

16. Herrera CA, Rada G, Kuhn-Barrientos L, Barrios X. Does ownership matter? An overview of systematic reviews of the performance of private for-profit, private not-for-profit and public healthcare providers. PLoS One. 2014;9(12):e93456. doi:10.1371/journal.pone.0093456

17. Basu S, Andrews J, Kishore S, Panjabi R, Stuckler D. Comparative performance of private and public healthcare systems in lowand middle-income countries: a systematic review. PLoS Med. 2012;9(6):e1001244. doi:10.1371/journal.pmed.1001244

18. Broomberg J. Managing the health care market in developing countries: prospects and problems. Health Policy Plan. 1994;9(3):237-251. doi:10.1093/heapol/9.3.237

19. International Monetary Fund (IMF). Macro-Fiscal Implications of Health Care Reform in Advanced and Emerging Economies. Washington: International Monetary Fund; 2010.

20. Le Grand J. The Other Invisible Hand: Delivering Public Services through Choice and Competition. Princeton, NJ: Princeton University Press; 2007.

21. Propper C. Competition, incentives and the English NHS. Health Econ. 2012;21(1):33-40. doi:10.1002/hec.1804

22. Bloom N, Propper C, Seiler S, Van Reenen J. the impact of competition on management quality: evidence from public hospitals. Rev Econ Stud. 2015;82(2):457-489. doi:10.1093/ restud/rdu045

23. Office of Health Economics (OHE). Competition in the NHS. Report of the office of health economics commission. London: Office of Health Economics; 2012. 